\section{A NEW SET OF MOLECULAR DESCRIPTORS}

O.A.. Blatova V.A. Blatov V.N. Serezhkin

Samara State University Chemistry Department Ac. Pavlov St. 1 SAMARA 443011 RUSSIA

A new set of criteria for quantitative analysis of molecular interactions is proposed resulted from the investigation of crystal structures of 808 picomplexes of rare-earth atoms (Ln). The set is based on the conceptions of atomic and molecular Voronoi-Dirichlet polyhedra and comprises: I. The criteria of existence of agostic and van der Waals contacts Ln...H-L between the complexing atom $\mathrm{Ln}$ and a ligand L. II. A set of criteria for ligands, namely: ligand total, valent and agostic solid angles, which are to be calculated with the faces of Voronoi-Dirichlet polyhedron of the Ln atom corresponding to all, only valent or only agostic Ln-L contacts, respectively; and ligand residual solid angle which is the difference between total and valent solid angles. III. A set of criteria for complexes as a whole including similar terms as the previous set, but relating to entire complex particle, to be calculated by summation of corresponding ligand solid angles for all ligands in a given complex. It is shown that the criteria of the first set allow one to improve the conclusions about existence or missing of agostic contacts. Seven different numerical combinations of the second and third sets of criteria were singled out, with which one can predict the composition and sterical stability of complex groups, the existence of intra- and intermolecular agostic and van der Waals interactions, and can judge about the capability of a ligand $\mathrm{L}$ to screen the central atom and to form the agostic contacts Ln...H-L.

Keywords: AGOSTIC INTERACTIONS, $\pi$-COMPLEXES
Acta Cryst. (2002). A58 (Supplement), C130

\section{COMPLEX COINAGE METAL (I) THIOSULFATES}

\section{E. J. Chan B.W Skelton A.H. White}

University of Western Australia Department of Chemistry 35 Stirling Hwy, Crawley PERTH W.A. 6009 AUSTRALIA

Crystals formed from aqueous solutions of thiosulfates (i.e. $\mathrm{Na}, \mathrm{K}$, and $\mathrm{NH}_{4}$ ) and coinage metal halides, may be relevant photographic 'fixation'. Previously known members of the isomorphous, tetragonal $I-42 d \mathrm{M}_{9}^{1} \mathrm{M}_{2}^{2} \mathrm{X}_{2}\left(\mathrm{~S}_{2} \mathrm{O}_{3}\right)_{2}, \mathrm{M}^{1}=$ group 1 cation $\mathrm{M}^{2}=(\mathrm{Cu}, \mathrm{Ag})$, series, including new members, have been isolated as eight complexes, the nitrates and the potassium adduct all new, containing the complex anion $\left[\mathrm{M}^{2}\left(\mathrm{SSO}_{3}\right)_{4}\right]^{7-}$ with quasi tetrahedral S-M-S geometry. Salts of the form $\mathrm{M}^{1}{ }_{2 \mathrm{n}-1} \mathrm{M}^{2}\left(\mathrm{~S}_{2} \mathrm{O}_{3}\right)^{\mathrm{n}} \cdot \mathrm{xH}_{2} \mathrm{O}, \mathrm{n}=1-3$, have also been defined: For $\mathrm{n}=3, \mathrm{M}^{2}=\mathrm{Cu}, \mathrm{M}^{1} / \mathrm{x}=\mathrm{K} / 2.25$ or $15 / 6, \mathrm{NH}_{4} / 6$, (and also for the $\left(\mathrm{NH}_{4}\right)_{4} \mathrm{Na} / 4 \mathrm{H}_{2} \mathrm{O} . \mathrm{MeOH}$ adduct) the arrays take the form $\mathrm{M}_{5}^{1}\left[\mathrm{Cu}\left(\mathrm{SSO}_{3}\right)_{3}\right] . \mathrm{xS}$ with distorted trigonal planar $\mathrm{CuS}_{3}$ coordination environments; the silver counterparts take the form $\mathrm{M}_{10}\left[\left(\mathrm{O}_{3} \mathrm{SS}\right)_{2} \mathrm{Ag}\left(\mu-\mathrm{SSO}_{3}\right)_{2} \mathrm{Ag}\left(\mathrm{SSO}_{3}\right)_{2}\right]$ for $\mathrm{M}^{1}=\mathrm{K}$, $\mathrm{NH}_{4}$. For $\mathrm{n}=2$ adducts have only been defined for $\mathrm{M}^{2}=\mathrm{Ag}$, the anions of the $\mathrm{M}=\mathrm{Na}, \mathrm{K}$ adducts being dimeric and polymeric: $\mathrm{Na}_{6}\left[\left(\mathrm{O}_{3} \mathrm{SS}\right)_{2} \mathrm{Ag}(\mu-\right.$ $\left.\left.\mathrm{SSO}_{3}\right)_{2} \mathrm{Ag}\left(\mathrm{SSO}_{3}\right)\right] \cdot 3 \mathrm{H}_{2} \mathrm{O}, \quad \mathrm{K}_{3}\left[\mathrm{Ag}\left(\mu-\mathrm{SSO}_{3}\right)_{2}\right] \cdot \mathrm{H}_{2} \mathrm{O} ;$ a polymeric copper 1 counterpart of the latter is found in $\mathrm{Na}_{5} \mathrm{Cu}\left(\mathrm{NO}_{3}\right)_{2}\left(\mathrm{~S}_{2} \mathrm{O}_{3}\right)_{2}=2 \mathrm{NaNO}_{3}$. Na 3 [Cu $(\mu$ $\left.\mathrm{SSO}_{3}\right)_{2}$ ]. For $\mathrm{n}=1, \mathrm{NaAgS}_{2} \mathrm{O}_{3}$, isolated as both the known mono-and a new anhydrate, exhibit a two-dimensional polymeric complex anion in both forms but with different contributing motifs, 6 and 4 membered rings respectively. $\left(\mathrm{NH}_{4}\right)_{13} \mathrm{Ag}_{3}\left(\mathrm{~S}_{2} \mathrm{O}_{3}\right)_{8} \cdot 2 \mathrm{H}_{2} \mathrm{O}$ takes the form $\left.\left(\mathrm{NH}_{4}\right)_{13}\left[\{\mathrm{OSS})_{3} \mathrm{Ag}\left(\mu-\mathrm{SSO}_{3}\right)\right\}_{2} \mathrm{Ag}\right]$, a linear central silver atom linking a pair of $\left[\mathrm{Ag}\left(\mathrm{SSO}_{3}\right)_{4}\right]^{7^{-}}$entities. In $\mathrm{Na}_{6}\left[\left(\mathrm{O}_{3} \mathrm{SS}\right) \mathrm{Ag}\left(\mu-\mathrm{SSO}_{3}\right)_{2} \mathrm{Ag}\left(\mathrm{SSO}_{3}\right)\right] \cdot 3 \mathrm{H}_{2} \mathrm{O}$, two binuclear anions are present as single clusters, the associated oxygen atoms disposed to one side, sandwiching layers of sodium ions.

\section{Keywords: COINAGE METAL THIOSULFATE CRYSTAL} STRUCTURE

\section{Acta Cryst. (2002). A58 (Supplement), C130}

\section{THE CRYSTAL AND MOLECULAR STRUCTURE OF (BIS N-OCTYL-} HYDROXYNAPHTHALDIMINATOCOPPER(II)

J. Costamagna ${ }^{1}$ A. Rios-Escudero ${ }^{1}$ M. Villagran ${ }^{1}$ F. Caruso ${ }^{2}$ J. Vargas ${ }^{3}$

Universidad De Santiago De Chile Faculty of Chemistry and Biology P.O.Box. 40, Santiago 33, SANTIAGO 7254758 CHILE

${ }^{1}$ Facultad De Quimica Y Biologia, Universidad De Santiago De Chile ${ }^{2}$ Istituto De Strutturistica Chimica, CNR, Rome, Italy. ${ }^{3}$ Universidad Metropolitana De Ciencias De La Educacion

$\mathrm{N}$-alkyl substituted Schiff bases with aliphatic long chains has been used to synthesize a variety of coordination compounds. Liquid crystals properties and Langmuir-Boldgett films has been intensively studied during the last years for these kind of materials (1). The present study show the synthesis, conventional characterization and X-ray structure for bis N-octylhydroxynaphthaldiminatocopper(II) complex. It crystallizes in the $R-3$ space group with $\mathrm{a}=\mathrm{b}=42.260(25) \AA, \mathrm{c}=5.162(3) \AA, \alpha=\beta=90^{\circ}, \gamma=120^{\circ}, \mathrm{Z}=9$, $\mathrm{V}=7984(14) \AA^{3}$. A total of 1389 reflections with $\mathrm{F}$ greater than four times $\sigma(\mathrm{F})$ were refined to a value of $\mathrm{R}=0.0664$. The molecular structure shows the copper atom in a planar environment and the octyl chains paralell each other.The crystal packing shows stacked units intermolecularly separated by $3.61 \AA$ A probably due to pi-pi electron interactions between naphtyl groups. References

(1) J.Nagel, U.Oertel, P.Friedel, H.Komber, D.Mobius, Langmuir, 13(1997)4693; C.C.Leznoff, A.B.P.Lever, Phthalocyanines: Properties and Applications, VCH, Vol. 1(Chp. 5), Vol. 2(Chp. 4), Vol. 3(Chp. 2), Vol. 3(Chp.3), Vol. 4(Chp.3),(1993).

Keywords: LIQUID CRYSTALS; LANGMUIR BLODGETT FILMS; SCHIFF BASE LIGANDS
Acta Cryst. (2002). A58 (Supplement), C130

EPR EVIDENCE FOR AN INTRAMOLECULAR C-F...V INTERACTION IN VANADA(IV)AZIRINE COMPLEXES BASED FROM X-RAY STRUCTURE DETERMINATIONS

B. Donnadieu R. Choukroun Ch. Lorber

Laboratoire De Chimie De Coordination UPR 8241 CNRS 205, Route De Narbonne TOULOUSE 31077 CEDEX FRANCE

The vanadocene $\mathrm{Cp}_{2} \mathrm{~V}$ is a valuable reactive complex able to react with alkynyl unit. The formation of a vanadocyclopropene moiety was already demonstrated when $\mathrm{Cp}_{2} \mathrm{~V}$ is reacted with an alkyne. New situation bonding can be reached with rich acetylenic chemistry in which the synthon $\mathrm{Cp}_{2} \mathrm{~V}$ play an important part in this concept. Extension of this research to the reactivity of the nitrile $\mathrm{CN}$ triple bond towards $\mathrm{Cp}_{2} \mathrm{~V}$ was recently achieved. Reaction of vanadocene $\mathrm{Cp}_{2} \mathrm{~V}$ with 'activated' nitrile R1CN.L (L: Lewis acid) yields the borane adduct of vanada(IV)azirine complexes $\mathrm{Cp}_{2} \mathrm{~V}$ (eta:2-R1C = N.L) $\left(\mathrm{L}=\mathrm{B}\left(\mathrm{C}_{6} \mathrm{~F}_{5}\right)_{3}\right.$ and $\left.\mathrm{B}\left(2,6-\mathrm{F}_{2} \mathrm{C}_{6} \mathrm{H}_{3}\right)_{3}\right)$. According to their structures, the $\mathrm{Cp}_{2} \mathrm{~V}$ vanadocene moiety is bonded to the nitrogen and carbon atoms of the ligand framework, to form the vanadaazirine ring. EPR studies in fluid solution were conducted on these complexes. A doublet of octets due to the coupling of the unpaired electron of the vanadium with the $51 \mathrm{~V}(\mathrm{I}=7 / 2)$ nucleus and to an additional hyperfine coupling to a ortho-F atom bared by the phenyl ring of the borane is elucidated by means of the different Lewis acid used in this work. A contrario, expected 8 line pattern EPR is observed with $\mathrm{L}=\mathrm{B}\left(3,4,5-\mathrm{F}_{3} \mathrm{C}_{6} \mathrm{H}_{2}\right)_{3}$, in which no ortho- $\mathrm{F}$ is present in the phenyl ring. This different EPR behavior gives evidence for the presence of a C-F...V interaction in fluid solution with $\mathrm{L}=\mathrm{B}\left(\mathrm{C}_{6} \mathrm{~F}_{5}\right)_{3}$ and $\mathrm{B}(2,6-$ $\left.\mathrm{F}_{2} \mathrm{C}_{6} \mathrm{H}_{3}\right)_{3}$. A dynamic process along the rotation of $\mathrm{B}-\mathrm{C}$ and N-B allows the ortho-fluorine atom to approach the vanadium centre. A model can be drawn to take into account this flexibility and V...F distances between V and ortho-F atoms are in the expected range for such an interaction. References

[1] R. Choukroun, C. Lorber, B. Donnadieu, B. Henner, R. Frantz, C. Guerin J. Chem. Soc., Chem. Commun., 1999, 1099.

[2] R. Choukroun, B. Donnadieu, C. Lorber, P-M Pellny, W. Baumann, U. Rosenthal, Chemistry, a European Journal, 2000, 24, 4505.

[3] R. Choukroun, P. Cassoux, Acc. Chem. Res, 1999, 32, 494.

[4] R. Choukroun, B. Donnadieu, J.S. Zhao, P. Cassoux, C. Lepetit, B. Silvi, Organometallics, 2000, 19, 1901. 